\title{
Towards a reconstruction of Antarctic climate over the last 2000 years
}

\author{
Barbara Stenni $i^{1,2}$, M. Curran ${ }^{3,4}$, C. Barbante ${ }^{1,2}$ and M. Frezzotti ${ }^{5}$
}

Venice, Italy, 3-4 September 2015

The PAGES Antarctica2k working group met for two days in September 2015 in Italy. Fifty scientists, including PhD and graduate students, coming from 12 countries shared thier expertise in paleoclimate reconstruction methods, dating, ice cores, marine and lake sediments, borehole temperature, polar meteorology and climate modeling. The first objective was to plan two community papers, one focusing on a climate reconstruction using isotopic records from ice cores and other proxy records, the other on a snow-accumulation-rate reconstruction using firn and ice-core records. The second objective was to investigate the possibility to reconstruct the Antarctic sea-ice variability over the past 2000 years using proxy data from both marine sediment and ice cores.

The meteorological observations in Antarctica, a continent one and a half times the size of Europe, started only during the 1957-1958 International Geophysical Year with most of the stations along the coast and only some in the interior. For this reason, Antarctica's past climate is only poorly documented. The interpretation of the isotopic profiles obtained from the ice cores allow to reconstruct the climate at different temporal scales from centuries to glacial-interglacial cycles, and can help fill in this spatial and temporal gap (Jouzel et al. 2007).

However, the snow deposition at the surface in Antarctica is spatially much less homogeneous than the original atmospheric precipitation (snowfall or diamond dust), due to wind erosion and redistribution, sublimation, and other processes during or after the precipitation events. For this reason, reconstructing past precipitation is a challenge.

The group discussed the state-of-the-art paleoclimate reconstructions from the high latitudes of the southern hemisphere. A particular emphasis was given to proxy interpretation and temperature calibration, highlighting the main challenges associated with ice-core water stable isotope records. The key factor controlling the isotopic proxy has been mainly related to temperature variations; however, this is not always straightforward and other processes acting on different spatial and temporal scales may influence

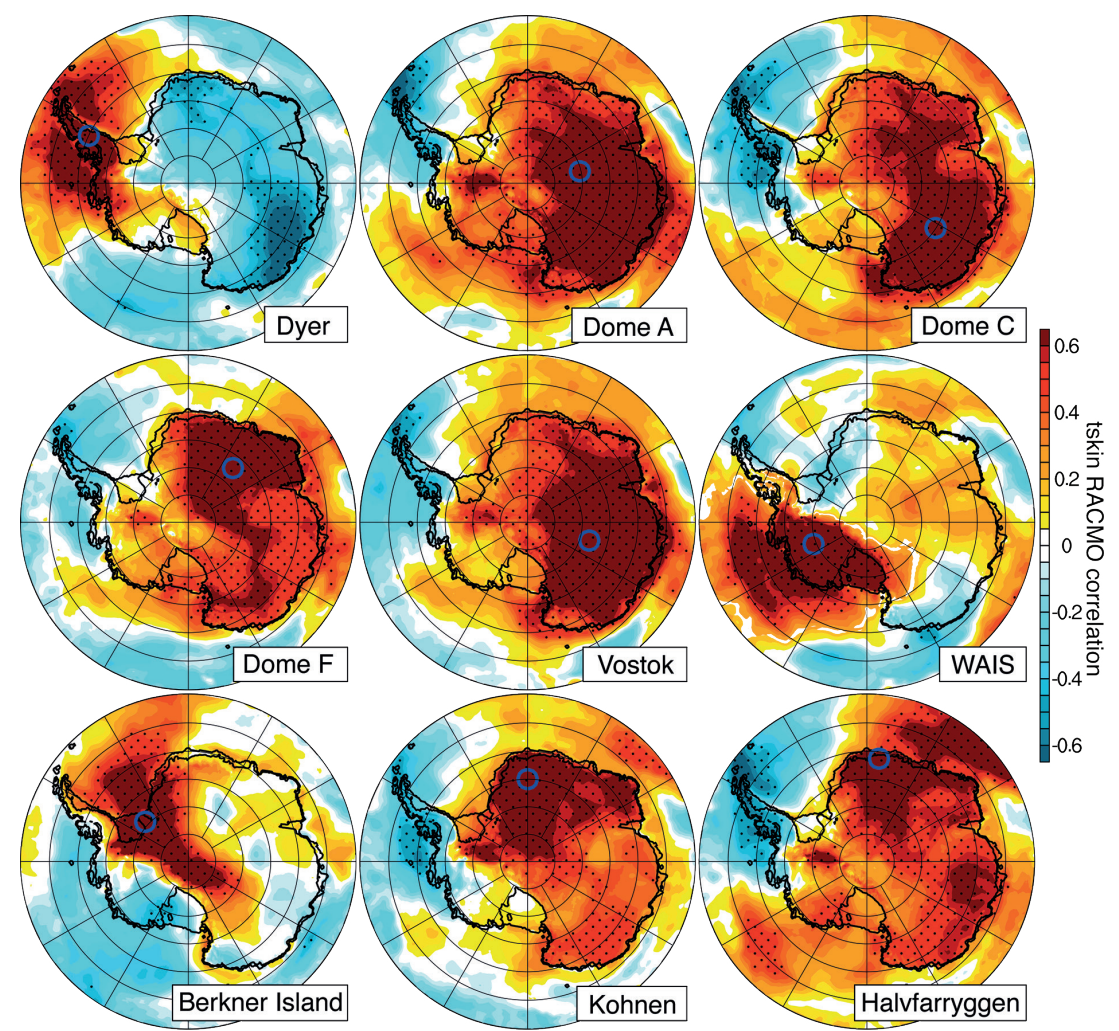

Figure 1: Spatial correlation map (annual values, 1979-2014) of surface temperature for major ice-core drilling sites as simulated by the regional atmospheric model RACMO2.3 at $27 \mathrm{~km}$ resolution (courtesy of Melchior van Wessem and Michiel van den Broeke, Utrecht University). this calibration. Early efforts to reconstruct the temperature history of Antarctica over the past 2000 years indicated that, at the continent-scale, Antarctica is the only land region where the long-term cooling trend of the last 2000 years has not yet been reversed by recent significant warming (PAGES 2k Consortium 2013). However, this reconstruction has large uncertainties and masks important regional-scale features of Antarctica's climate evolution.

The group decided to expand the paleoclimate database and use new reconstruction methodologies aiming to reconstruct the climate of the past 2000 years at decadal scale and on a regional basis. Seven distinct climatic regions have been selected: the Antarctic Peninsula, the West Antarctic Ice Sheet, the East Antarctic Plateau, and four coastal domains of East Antarctica. This approach, supported by climate-model results (Fig. 1), will be applied to both isotopic and snow-accumulation-rate reconstructions.

The synthesis from ice-core records will be compared and evaluated against proxy data from marine and coastal terrestrial (e.g. lake, peat) records to shed light about possible different patterns between coastal/ low-elevation and high-elevation regions in Antarctica. Moreover, a call for sea-ice proxy data has been launched and people within the sea-ice working group are working on implementation of the database.

If you would like to contribute to the current effort, or contribute data, contact working group leader Barbara Stenni.

\section{ACKNOWLEDGEMENTS}

The meeting was sponsored by PAGES, PNRA and DAIS (Ca' Foscari University, Venice), under the patronage of SISC

\section{AFFILIATIONS}

Department of Environmental Sciences, Informatics and Statistics, Ca' Foscari University of Venice, Italy ${ }^{2}$ Institute for the Dynamics of Environmental

Processes, CNR, Venice, Italy

${ }^{3}$ Australian Antarctic Division, Hobart, Australia

${ }^{4}$ Antarctic Climate and Ecosystems CRC, University of

Tasmania, Hobart, Australia

${ }^{5}$ ENEA, CR Casaccia, Roma, Italy

\section{CONTACT}

Barbara Stenni: barbara.stenni@unive.it

REFERENCES

Jouzel J et al (2007) Science 317: 793-796

PAGES 2k Consortium (2013) Nature Geoscience 6 : 339-346 